\section{Atividade Colinesterásica em Tiveóide de Ratos: Resposta a Uma Sobrecarga de Iodo}

\section{RESUMO}

A utilização do lodo antes de cirurgias de tireóide visa a redução do fluxo sanguíneo para a glândula e melhora da hemostasia. Para tentar elucidar o mecanismo pelo qual a vasoconstricção se instala. foi determinada a atividade colinesterásica em tireóides de ratos Wistar machos (240-250g de peso corporal), submetidos a uma sobrecarga oral de iodo pela oferta de soluçâo aquosa de iodato de potássio $\left(\mathrm{KlO}_{3} 3 \mu \mathrm{g} / \mathrm{ml}\right)$ como água de beber, por 3 e 7 dias; o grupo controle recebeu água durante o mesmo período. Ao final do tratamento os animais foram sacrificados e suas tireóides retiradas, limpas e pesadas; o rim direito e o lobo direito do figado foram usados como controles da atividade colinesterásica. Foram preparados homogeneizados em tampão fosfato ( $\mathrm{pH}=8,0$ ), contendo $0,32 \mathrm{M}$ de sacarose, na concentração de $40 \mathrm{mg}$ de tecido $/ \mathrm{ml}$. Os ratos que receberam $\mathrm{KIO}_{3}$ por 7 dias tiveram diminuição no peso da tireóide quando comparados aos controles $(p<0,05)$, o mesmo não acontecendo aos 3 dias de tratamento. Aos 3 dias de tratamento, a atividade colinesterásica tireóidea fol de $5,38 \pm 0,36 \mathrm{nmol} / \mathrm{min} . \mathrm{mg}$ para o grupo controle $(n=12)$ e de $5,43 \pm 0,98$ $\mathrm{nmol} / \mathrm{min}$.mg para o grupo tratado $(\mathrm{n}=11)(\mathrm{NS})$; valores bastante similares foram também encontrados com o tratamento de 7 dias (controles: $5,42 \pm 0,27 \mathrm{nmol} / \mathrm{min} . \mathrm{mg}(\mathrm{n}=8)$ e tratados: $5,63 \pm 0,88 \mathrm{nmol} / \mathrm{min} . \mathrm{mg}$ $(n=8)$; NS). Nossos resultados sugerem que, a despeito da vasoconstricção, não há alteração da atividade colinesterásica na tireóide em resposta a sobrecarga oral de iodo. (Ara Bras Endocrinol Metab 2000;44/4: 347-351)

Unitermos: Tireóide; Atividade colinesterásica; lodo; Excesso de iodo

\section{artigo original}

\author{
Heraldo E. Borges \\ Andréia C.P. Martins \\ Paulo C.F. Mathias \\ Roberto Z. Esteves
}

Departamento de Biologia Celulare Genética e Departamento de

Medicina, Universidade Estadual de Maringá (UEM), Maringá, PR.

\begin{abstract}
lodine is given during the 7 to 10 days immediately preceding thyroid operation to decrease the vascularity of the gland, making it less friable and decreasing difficulties for the surgeon. The present work evaluated cholinesterase activity in rat thyroid glands on high iodine intake to establish a possible relationship between high lodineinduced vasoconstriction and parasympathetic activity. Male Wistar rats weighing $240-250 \mathrm{~g}$ were given $\mathrm{KIO}_{3}(3 \mu \mathrm{g} / \mathrm{ml})$ as drinking water for 3 and 7 days; the control groups received tap water. At the end of the treatment period rats were sacrificed and their thyroid glands taken out, washed and weighed; the liver and the kidney were used as parameters of cholinesterase activity. Rats that received $\mathrm{KIO}_{3}$ for 7 days had a decreased thyroid gland weight compared to controls $(p<0.05)$. However, no significant decrease in thyroid weight occurred after 3 days of treatment. At 3 days thyroid gland cholinesterase activity ( $\mathrm{nmol}$ of acetylthiocholine hydrolysed/min.mg of protein) was $5.38 \pm 0.36$ (mean $\pm S D$ ) in the control group $(n=12)$ and $5.43 \pm 0.98$ in the treated group $(n=11)$ (NS). After 7 days of treatment cholinesterase activity was $5.42 \pm 0.27$ in the control group $(n=8)$ and $5.63 \pm 0.88$ in the treated group $(n=8)(N S)$. Our results suggest that the iodine-induced thyroid gland vasoconstriction is not due to changes in thyroid
\end{abstract}

Recebido em 11/09/1999 Revisado em 18/02/2000 Aceito em 10/04/2000 


\section{cholinesterase activity. (Arq Bras Endocrinol Metab 2000;44/4: 347-351)}

Keywords: Thyroid gland; Cholinesterase activity; lodine; lodine excess

A BIOSSÍNTESE DE hORMÓNIOS TIREÓdDEOS de (HT) dependente da presença de quantidades adequadas de iodo. Durante deprivação de iodo, os níveis séricos de HT são mantidos constantes devido à mobilização de consideráveis reservas de $\mathrm{T}_{4} \mathrm{e}_{3}$ presentes no colóide, pela otimização do transporte de iodeto para o interior da célula folicular tireóidea e aumentando a eficiência da síntese de iodotironinas catalisada pela enzima tireoperoxidase (1). Da mesma maneira, durante ingestão elevada de iodo, níveis estáveis de HT são mantidos na corrente sanguínea devido, em parte, a uma autorregulação do transporte de iodeto, o que limita sua captação e organificação pelas células foliculares $(2,3)$.

A tireóide recebe um fluxo sanguíneo que corresponde a cerca de cinco vezes o seu peso, sendo um dos órgãos mais vascularizados do organismo. Este suprimento sanguíneo elevado se deve à necessidade da tireóide ser exposta a uma quantidade adequada de iodo a fim de manter a função normal da glândula. Conseqüentemente, a alteração do fluxo sangüíneo é um importante fator para manter os níveis de HT constantes em condições de variação da ingestão de iodo (4). Altas concentrações de iodo são geralmente administradas durante os 7 a 10 dias anteriores à intervenção cirúrgica na tireóide, com o objetivo de reduzir seu fluxo sangüíneo $(5,6)$. A glândula torna-se mais firme, melhorando as condições cirúrgicas.

A tireóide é ricamente inervada por fibras colinérgicas originadas do nervo vago. Estas fibras estão presentes em volta e entre os folículos e vasos sanguíneos tireóideos (7-9). O estímulo colinérgico promove vasodilatação, inibição da liberação de HT (10) e acúmulo de óxido nítrico (11) e GMP cíclico (12-14) no tecido tireóideo. A acetilcolinesterase (AchE) tem papel importante na neurotransmissão colinérgica, por ser responsável pela hidrólise da acetilcolina (Ach), controlando o nível de Ach presente na fenda sináptica (15). A AchE está localizada na membrana pós-sináptica (16) e o número de moléculas disponíveis parece ser controlado pela interação entre a Ach e seu receptor (17). Sua atividade pode ser regulada positivamente ou negativamente $(18,19)$. Com isso a AchE pode ser utilizada como indicador do tônus parassimpático.

Com base no efeito vasoconstritor do iodo (em altas concentrações) na tireóide e nos efeitos da estimulação colinérgica, o presente trabalho procurou avaliar a existência de uma relação entre vasoconstrição induzida pelo iodo e tônus parassimpático.

\section{MATERIAL E MÉTODOS}

\section{Animais}

Ratos Wistar machos, pesando $240-250 \mathrm{~g}$ foram obtidos do Biotério Central da Universidade Estadual de Maringá (UEM). Os animais receberam solução aquosa de $\mathrm{KIO}_{3}(3 \mu \mathrm{g} / \mathrm{ml})$ como água de beber, por 3 e 7 dias, enquanto os grupos controle receberam apenas água. Ambos os grupos tiveram livre acesso à ração (NUVILAB) que continha $2 \mathrm{ppm}$ (partes por milhão) de iodo. Durante o período de tratamento, os animais foram mantidos em biotério com controle de temperatura $\left(23 \pm 2^{\circ} \mathrm{C}\right)$ e fotoperíodo de $12 \mathrm{~h}$ de claro/escuro (luz de 07:00 às 19:00h).

\section{Preparo dos tecidos}

Ao final do tratamento os animais foram anestesiados com Nembutal ${ }^{\circledR}(40 \mathrm{mg} / \mathrm{kg})$; em seguida a glândula tireóide e amostras do fígado e rim foram retirados e mantidos em solução salina $(\mathrm{NaCl} 0,9 \%)$ sob baixa temperatura $\left(4^{\circ} \mathrm{C}\right)$. Após a retirada dos órgãos os animais foram sacrificados. Os tecidos foram isolados, pesados e recolhidos em tampão fosfato $0,01 \mathrm{M}, \mathrm{pH}$ 8,0 , contendo $0,32 \mathrm{M}$ de sacarose. As amostras de fígado e rim, foram obtidas como parâmetros de atividade colinesterásica alta e baixa, respectivamente.

\section{Preparo dos homogeneizados}

Os homogeneizados $(40 \mathrm{mg} / \mathrm{ml})$ foram preparados $\mathrm{em}$ tampão fosfato $0,01 \mathrm{M}(\mathrm{pH}=8,0)$, contendo $0,32 \mathrm{M}$ de sacarose, utilizando homogenizador GLAS-COL ${ }^{\circledR}$ (GKH-GT MOTOR CONTROL) e centrifugados a $6.000 \mathrm{rpm}$ durante 2 minutos. Os sobrenadantes foram coletados e armazenados a $-20^{\circ} \mathrm{C}$.

\section{Determinação da atividade colinesterásica}

A atividade colinesterásica foi determinada pelo método descrito por Ellman et al. (20), usando iodeto de acetiltiocolina (Asch) na concentração final de $0,5 \mathrm{mM}$ como substrato. Todas as soluções foram mantidas a $4^{\circ} \mathrm{C}$ durante a dosagem e as amostras foram analisadas em duplicata. As cubetas continham um volume final de 1560ul: 1300ul de tampão fosfato, $200 \mu \mathrm{l}$ de homogeneizado da glândula tireóide, $50 \mu \mathrm{l}$ de ácido 5,5 ' ditio-bis-2-nitrobenzóico (DTNB) e 10ul de Asch. Para a avaliação da atividade colinesterásica em fígado e rim, foram utilizados $100 \mu \mathrm{l}$ e $150 \mu \mathrm{l}$ de homogeneizados, respectivamente. $\mathrm{O}$ blank era composto por tampão fosfato, DTNB e Asch. A determinação do 
conteúdo de proteínas foi feito pelo método de Lowry et al. (21); albumina bovina foi utilizada como padrão. Os resultados foram expressos como nmoles de Asch hidrolisados por minuto e miligrama de proteína (nmol/min.mg prot.).

\section{Análise estatística}

Os resultados são apresentados como média \pm desviopadrão. O teste $t$ de Student foi usado para determinar diferenças estatísticas $(\mathrm{p}<0,05)$ entre grupo controle e tratado e o teste ANOVA foi usado para comparar a atividade colinesterásica entre os tecidos (rim, fígado e tireóide).

\section{Materiais}

Todos os reagentes foram obtidos da Sigma Chemical Co. (St. Louis, MO, USA), com exceção do iodato de potássio (Merck - Darmastadt, Germany) e da sacarose (Vetec - Duque de Caxias, RJ, Brasil).

\section{RESULTADOS}

Os animais tratados com $\mathrm{KIO}_{3}$ durante 3 dias não apresentaram diferença estatística na atividade colinesterásica na tireóide; isto também foi observado para o rim e fígado. No tratamento de 7 dias, também não ocorreu alteração na atividade colinesterásica (tabela 1) (tireóide $\mathrm{p}=0,53$; rim $\mathrm{p}=0,51$; fígado $\mathrm{p}=0,66)$. Quando os diferentes tratamentos (3 e 7 dias) foram comparados, também não se encontrou diferença significativa entre eles.

A atividade colinesterásica no figado $(3,32 \pm 0,76 \mathrm{nmol} / \mathrm{min} . \mathrm{m}$ prot $)$ corresponde a aproximadamente $62 \%$ da encontrada na tireóide $(5,38 \pm 0,36$ $\mathrm{nmol} / \mathrm{min} . \mathrm{mg}$ prot $)$ e no $\mathrm{rim}(1,61 \pm 0,26 \mathrm{nmol} /$ min.mg prot) a atividade corresponde a $30 \%$ da encontrada na tireóide $(p<0,0001)$.
Os ratos que receberam $\mathrm{KIO}_{3}$ durante 7 dias tiveram diminuição significativa no peso da tireóide (figura 1). No entanto, esta alteração não ocorreu durante o tratamento de 3 dias (controle: $52,36 \pm 8,75$ mg; tratado: $49,74 \pm 6,35 \mathrm{mg}$ ). Quando se relacionou o peso da tireóide ao peso corporal, os resultados foram semelhantes.

\section{DISCUSSÃO}

Para a realização de nossos experimentos foram utilizados tratamentos com dieta elevada de iodo, nos períodos de 3 e 7 dias, pois durante o processo de instalação do fenômeno de vasoconstrição induzido por iodo poderia haver alteração transitória ou tempodependente na atividade colinesterásica. Apesar da vasoconstrição induzida pelo iodo ser demonstrada por vários autores $(4,6,22)$, a natureza do processo pelo qual ele se instala ainda é incerto.

Nossos dados mostraram alta atividade colinesterásica na tireóide, quando comparados aos outros tecidos, corroborando os achados de vários autores (7-9) que demonstraram a presença de fibras parassimpáticas em tireóides de camundongos e humanos. Estes resultados sugerem uma influência do sistema nervoso parassimpático na função tireóidea.

Ao final do tratamento de 7 dias houve diminuição do peso da glândula, o que não ocorreu durante o tratamento de 3 dias. Com base nestes dados, pode-se propor que a diminuição do peso da tireóide foi tempo-dependente; o mecanismo permanece incerto.

Estudos anteriores em tireóide, mostraram que o estímulo por agonistas colinérgicos promove acúmulo de GMPc (12-14). Esteves e cols. (11) realizaram estudos em tireóide de cão e verificaram que o acú-

Tabela 1. Atividade colinesterásica em tireóide, figado e rim de ratos submetidos a dieta elevada de iodo durante 3 e 7 dias.

\begin{tabular}{lcc}
\hline & ATIVIDADE COLINESTERÁSICA (nmol/min.mg Prot) & \\
\hline RIM & CONTROLE & \\
3 dias & $1,61 \pm 0,26$ & $1,42 \pm 0,28 \mathrm{NS}$ \\
7 dias & $1,63 \pm 0,21$ & $1,72 \pm 0,38 \mathrm{NS}$ \\
FíGADO & & \\
3 dias & $3,32 \pm 0,76$ & $3,34 \pm 0,88 \mathrm{NS}$ \\
7 dias & $3,35 \pm 0,47$ & $3,24 \pm 0,50 \mathrm{NS}$ \\
TIREÓIDE & & \\
3 dias & $5,38 \pm 0,36$ & $5,43 \pm 0,97 \mathrm{NS}$ \\
7 dias & $5,42 \pm 0,27$ & $5,36 \pm 0,88 \mathrm{NS}$ \\
\hline
\end{tabular}

NS=Não significativo

* Resultados apresentados como média \pm desvio-padrão, sendo expressos em nmoles de Asch hidrolisada por minuto e miligrama de proteina $(n=8$ al2). 


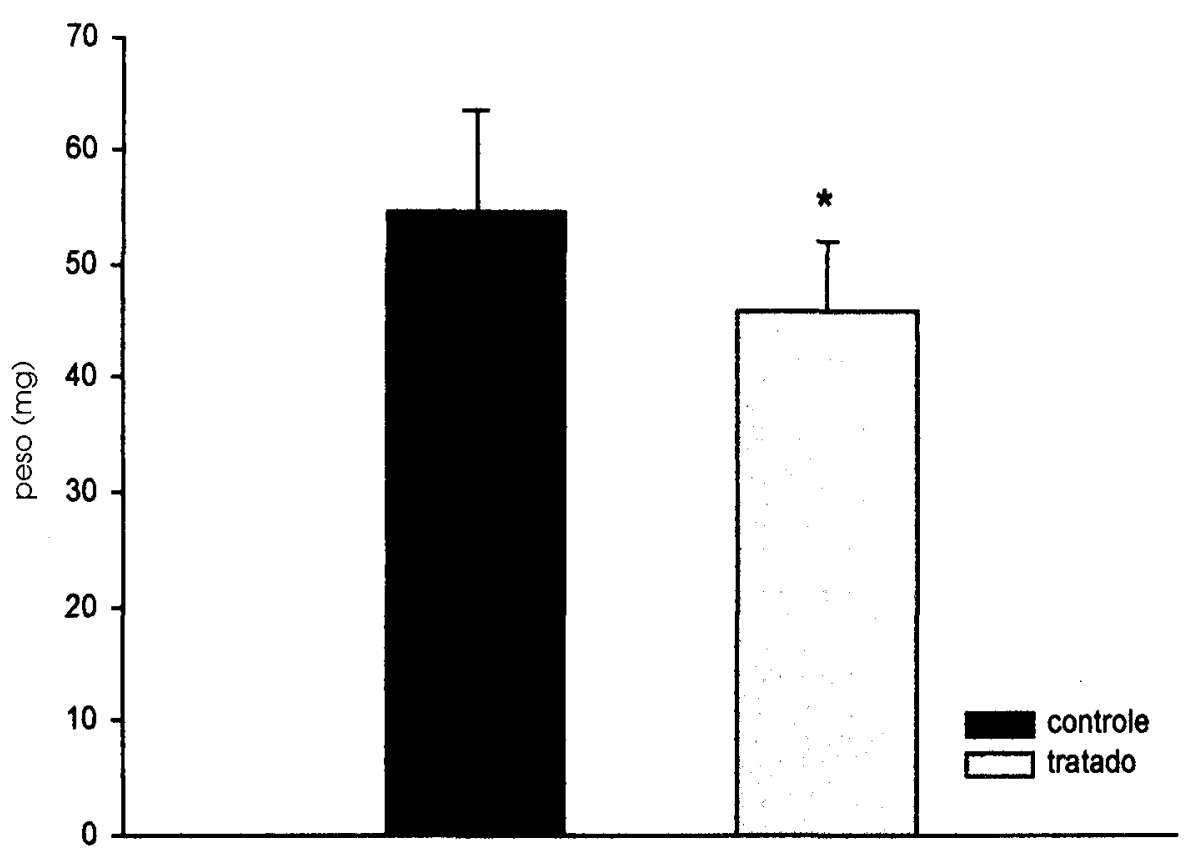

Figura 1. Peso da glândula tireóide (mg) de ratos tratados durante 7 dias com $\mathrm{KIO}_{3}(3 \mu \mathrm{g} / \mathrm{ml})$. Os dados representam média \pm desvio-padrão $(n=8) .{ }^{*} p<0,05$

mulo de GMP cíclico induzido pela carbamilcolina era bloqueado por inibidores da NO sintase e da guanilato ciclase. A enzima NO sintase depende de vários cofatores, entre eles o NADPH (23). Stuehr e cols. (24) mostraram que o DPI (difenileno-iodônio), um inibidor de enzimas dependentes de NADPH, inibe a ativação da NO sintase. Com base nestes estudos sugerimos que, durante elevada ingestão de iodo, compostos aromáticos iodados, como o DPI, poderiam estar aumentados e então diminuir o acúmulo de GMPc. Hoje sabe-se que o efeito vasodilatador do NO é mediado por GMPc (25), o que reforça a hipótese que a diminuição do acúmulo de GMPc poderia ser um processo importante na instalação do fenômeno de vasoconstrição. Esta hipótese deverá ser testada nos nossos trabalhos subseqüentes.

Nossos resultados sugerem que, a despeito da vasoconstrição, não há alteração da atividade colinesterásica na tireóide em reposta a sobrecarga de iodo.

\section{AGRADECIMENTOS}

Trabalho realizado com auxílio financeiro do CNPq, processo $\mathrm{N}^{\circ}$ 52.1815/96-7 (PCFM) e processo $\mathrm{N}^{\mathrm{o}}$ 300569/97-1(RZE).

\section{REFERÊNCIAS}

1. Ingbar $\mathrm{SH}$. Autoregulation of the thyroid: response to lodide excess and depletion. Mayo Clin Proc 1972;47:814-23.

2. Chazenbalk GD, Valsecchi RM, Krawiec L, Burton $G$, Juvenal GJ, Monteagudo $E$, et al. Thyroid autoregulation: Inhibitory effects of iodinated derivatives of arachidonic acid on iodine metabolism. Prostaglandins 1988:36: 163-72.

3. Sherwin JR, Price DJ. Autoregulation of thyroid transport: evidence for the mediation of protein synthesis in iodineinduced suppression of iodide transport. Endocrinology 1986; 1 19:2553-9.

4. Michalkiewicz M, Huffman LJ, Connors JM, Hedge GA. Alterations in thyroid blood flow induced by varying levels of iodine intake in the rat. Endocrinology 1989;125:5460.

5. Wikin TJ, Swanson Beck J, Michie W. Does preoperative iodide treatment for thyrotoxicosis bring about involution? J Clin Pathol 1977;30:99-102.

6. Chang DCS, Wheeler MA, Woodcock JP, Curley I, Lazarus JR, Fung $\mathrm{H}$, et al. The effect of preoperative Lugol's iodine on thyroid blood flow in patients with Graves' hyperthyroidism. Surgery 1987; 102:1055-61.

7. Amenta F, Caporuscio D, Ferrante F, Porcelli F, Zomparelli $M$. Cholinergic nerves in the thyroid gland. Cell Tiss Res 1978;195:367-70. 
8. Melander A, Sundler F. Presence and influence of cholinergic nerves in the mouse thyroid. Endocrinology 1979: 105:7-9.

9. Van Sande J, Dumont JE, Melander A, Sundler F. Presence and influence of cholinergic nerves in the human thyroid. J Clin Endocrinol Metab 1980;51:500-2.

10. Maayan ML, Vopert EM, From A. Acetylcholine and norepinephrine: compared actions in thyroid metabolism. Endocrinology 1993;1 12:1358-62.

11. Esteves RZ, Van Sande J, Dumont JE. Nitric oxide as a signal in thyroid. Mol Cell Endocrinol 1992;90:R1-R3.

12. Yamashita K, Field JB. Elevation of cyclic guanosine $3^{\prime} 5^{\prime}$ monophosphate levels in dog thyroid slices caused by acetylcholine and sodium fluoride. J Biol Chem 1972;247:7062-6.

13. Van Sande J, Decoster C, Dumont JE. Effects of carbamylcholine and ionophore A-23187 on cyclic $3^{\prime} 5^{\prime}$ AMP and cyclic 3'5' GMP accumulation in dog thyroid slices. Mol Cell Endocrinol 1979;14:45-57.

14. Brandi ML, Rotella CM, Tanini A, Toccafondi R, Aloj SM. Cholinergic control of cyclic nucleotide metabolism in human thyroid cells. J Endocrinol Invest 1987;10:451-8.

15. Brimijoin S. Molecular forms of acetylcholinesterase in brain, nerve and muscle: nature localization and dynamics. Prog Neurobiol 1983:21:291-322.

16. Mc Bride WJ, Cohen H. Cytochemical localization of acetylcholinesterase on isolated synaptosomes. Brain Res 1972:41:489-93

17. Fernandez HL, Hodges-Savola CA. Trophic regulation of acetylcholinesterase isoenzymes in adult mammalian skeletal muscles. Neurochem Res 1992;17:1 15-24.

18. Moudgil VK, Kanungo MS. Effect of age of the rat on induction of acetylcholinesterase of the by $17 \beta$-estradiol. Biochem Biophys Acta 1973;329:21 1-20.
19. Battie CN, Moran N Sympathectomy alters acetylcholinesterase expression in adult rat heart. Cardiovasc Res 1990:24:335-9.

20. Ellman GL, Courtney KD, Andres JrV. Featherstone RM. A new and rapid colorimetric determination of acetylcholinesterase activity. Biochem Pharmacol 1961:7:8895.

21. Lowry $\mathrm{OH}$, Rosebrough NJ, Farr AL, Randall RJ. Protein measurement with Folin phenol reagent. J Biol Chem $1951 ; 193: 265-75$

22. Brownlie BEW, Turner JG, Ellwood MA, Rogers TGH, Armstrong, DI. Thyroid vascularity-documentation of the iodide effect in thyrotoxicosis. Acta Endocrinol (Copenh) 1977:86:317-22.

23. Moncada S, Palmer RMJ, Higgs EA. Nitric oxide: physiology, pathophysiology, and pharmacology. Pharmacol Rev 1991:43:109-38.

24. Stuehr DJ, Fasehun AO, Kwon NS, Gross SS, Gonzales JA, Levi R, et al. Inhibition of macrophage and endothelial cell nitric oxide synthase by diphenileneiodonium and its analogs. FASEB J 1991:5:98-103.

25. Moncada S, Higgs A, Furchgott R. XIV international Union of Pharmacology: Nomenclature in nitric oxide research. Phamacol Rev 1997;49: 137-42.

\section{Endereço para correspondência:}

Roberto Zonato Esteves

Universidade Estadual de Maringá (UEM) -

Departamento de Medicina

Avenida Mandacaru 1590

87.080-000 Maringá, PR

Tel/Fax: (044) 225-8484

e.mail: roberto_esteves@wnet.com.br 